\title{
ME LLAMO DOMINGA. \\ RELATO DE UNA MUJER EN FASE TERMINAL
}

E. Begoña García Navarro* Rosa Pérez Espina** Sonia García Navarro***

*Enfermera Área Hospitalaria Juan Ramón Jiménez. Universidad de Huelva **Enfermera, Hospital Vázquez Díaz Huelva. ***Enfermera, Distrito Huelva-Costa Ganadora Premio "Mejor Comunicación Oral"

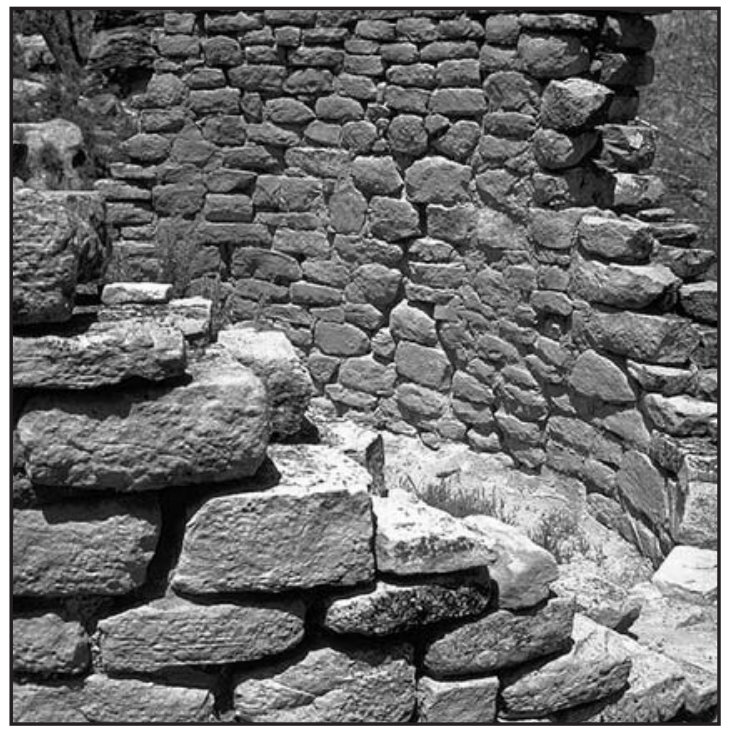

MY NAME IS DOMINGA. STORY OF A TERMINALLY-ILL WOMAN

\section{SUMMARY}

$\mathrm{T}$

The care of the oncological patient has been and continues being subject of many studies. This story aims to give expression to the needs these patients perceive as real during the process of their illness, regardless of their prognosis. In the development of the disease, the fact of being a woman arises role conflicts within the family and above all in the woman herself, causing a mental duality of guiltiness for her situation and perhaps fatal ending; besides that is the body image and female identity disorder, social and family pressure, and trying to keep up the appearances as if nothing was happening whilst life slips away.

Key words: Biographical story, terminally-ill, coping with death.

\section{CHAMO-ME DOMINGA. RELATO DE UMA MULHER EM FASE TERMINAL}

\section{RESUMO}

O cuidado ao enfermo oncológico tem sido e é objeto de múltiplos estudos. O relato que se apresenta quer traduzir as necessidades que estes enfermos possuem como reais no processo de sua enfermidade, qualquer que seja seu prognóstico. $\mathrm{O}$ fato de ser mulher no desenvolvimento de uma enfermidade, suscitam-se conflitos de papéis na família e, sobretudo, na própria mulher, criando uma dualidade mental de culpabilidade diante de sua situação de enfermidade e em alguns casos diante do fatal desenlace; ademais, acrescentam-se a este entorno a imagem corporal, a identidade feminina, as pressões familiares e sociais em buscar aparentar que não ocorre nada, enquanto a vida se lhe escapa.

Palavras-chave: Relato biográfico, enfermo terminal, enfrentamento diante da morte.

\section{RESUMEN}

$\square$ 1 cuidado al enfermo oncológico ha sido y es objeto de múltiples estudios, el relato que se presenta quiere plasmar las necesidades que estos enfermos plantean como reales en el proceso de su enfermedad, sea cual sea su pronóstico. El hecho de ser mujer en el desarrollo de una enfermedad suscita conflictos de roles en la familia y sobretodo en la propia mujer creando una dualidad mental de culpabilidad ante su situación de enfermedad y en algunos casos ante un fatal desenlace; además se le añade el trastorno de la imagen corporal, de la identidad femenina, de las presiones familiares y sociales, de intentar aparentar que no ocurre nada mientras la vida se escapa. 
Palabras Clave: Relato biográfico, enfermo terminal, afrontamiento ante la muerte.

\section{INTRODUCCIÓN}

Vivimos en una sociedad en la que el culto al cuerpo y la evasión del dolor son predominantes en nuestras vidas, nos alejamos de todo aquello que nos provoque dolor e intentamos solucionar con sustancias químicas todo lo que se nos escapa de lo racional o placentero. Es por ello, que en nuestra cultura no nos preparamos para afrontar la muerte como tramo final de nuestra existencia. Al no estar preparado para ello, las reacciones presentan sensaciones negativas, de gran dolor y sentimientos de culpa y negación por no haber sabido acompañar al moribundo en el tramo final de su vida.

Cuidando a enfermos terminales aprendemos a descubrirlos, a superar nuestros prejuicios y temores, a escucharlos y no oírlos, a darles la información que solicitan sin mentirles, y a estrecharles la mano hasta el final. Pensamos que conocer la percepción de los pacientes terminales respecto a sus miedos, sus sentimientos y sus sensaciones nos ayudarán tanto a los profesionales de la salud cómo a los cuidadores de pacientes terminales y a todos en general a sentir la muerte cómo parte final de la existencia y así poder afrontarla de manera más madura disfrutando también de este último paseo. Por este motivo decidimos realizar un estudio que nos permitirá plantear estrategias futuras para cuidar mejor a nuestros pacientes terminales y a sus familiares, influyendo esto en la disminución del gasto hospitalario gracias al confort físico, mental y emocional de los pacientes y familiares en sus domicilios. De la misma manera también se beneficiarán de este estudio aquellos profesionales, pacientes y familiares que se enfrentan a la muerte en los hospitales.

Dado que este estudio pretende obtener un conocimiento a través de las percepciones de los enfermos terminales, oncológicos o no, es necesario utilizar una metodología cualitativa, que nos aporte una amplia información sobre el sufrimiento espiritual y las estrategias generadas por éstos para afrontar la situación en la que se encuentran

El relato que se presenta a continuación está enmarcado dentro de esta investigación, la experiencia de estar cercana a la muerte, provoca un gran revuelo personal que es totalmente personal e individualizado, cada persona utiliza unas estrategias para afrontar esta difícil situación, al igual que sus familiares, cada uno de los afrontamientos son distintos. El caso que se describe a continuación es relevante no sólo por las características de la informante, sino por el espíritu de lucha que mantuvo hasta el final de sus días. Con su generosidad en su discurso cautivó al equipo investigador, nos invitó a permanecer con ella, a seguir su caso hasta el desenlace final; quería que su experiencia sirviera para que otras personas que pasaran por su misma situación tuvieran un referente y se sintiesen acompañadas. El poderla conocer y realizar con ella su último viaje nos ha enriquecido de forma profesional y sobretodo personal. Durante nuestras entrevistas, conseguimos introducirnos en el pensamiento de una mujer con cáncer terminal, llegando a saber cómo se siente ella, cómo ve ella el sufrimiento de su familia, cómo valora los servicios sanitarios y cómo de importante es su propio afrontamiento y el de su familia para su calidad de vida en sus últimos días.

\section{BIBLIOGRAFÍA}

- Bayes R. (2004) Morir en paz evaluación de los factores implicados. Med Clin; 122(14):539-41

(Se hace una reflexión sobre la necesidad de una investigación metodológicamente seria del proceso de morir, con un profundo respeto por el ser doliente del que pretendemos extraer conocimiento sobre los factores que le facilitan o dificultan tener una muerte en paz y al que, simultáneamente, por encima de la obtención de datos, debemos ayudar con las mejores armas de que dispongamos en cada momento).

- Palomar, C., Merino, D. (2003) El duelo de los cuidadores principales de pacientes oncológicos atendidos en domicilio. Metas de enfermería, ISSN 1138-7262, №. 57: 61-64.

(Estudio que valora la superación del duelo de los cuidadores principales de pacientes oncológicos atendidos en el domicilio, mediante entrevista en profundidad, observándose que la mayoría de los entrevistados sufren duelo no resuelto o duelo disfuncional, haciéndonos reflexionar sobre la importancia de la formación sobre intervenciones en duelo, para ofrecer cuidados enfermeros de calidad).

\section{RELATO BIOGRÁFICO \\ EL MATRIARCADO. MI MADRE Y YO}

Me llamo Dominga, tengo 42 años, estoy casada y tengo 3 hijos, de 21, 19 y 6 años y una sobrina de 15 años que vive con nosotros. Vivimos aquí en La Peña, al ladito de la Virgen. Mi madre vive también con nosotros, no sé qué haría sin ella. Se quedó viuda muy joven y, desde entonces, las dos nos hicimos cargo de mis hermanos. Todos hemos 
trabajado mucho, y ella más que nadie. Mi madre ha sufrido mucho en la vida, pero es una mujer muy fuerte, y una santa. En mi familia somos como una piña: mis hermanos, mi madre y yo con mi marido y mis hijos. "Soy un gran pilar en mi familia, yo soy el núcleo para apoyar y tomar decisiones".

Soy muy joven y ya hace dos años que lucho contra mi cáncer. He sido siempre una mujer muy activa, luchadora y muy optimista, muy positiva: he tirado siempre del carro... en el pueblo todos me conocen porque me he llevado trabajando toda mi vida, desde que era muy pequeña.

\section{EL CÁNCER, UNO MÁS EN MI FAMILIA}

Lo hemos pasado muy mal en la familia. Mi padre murió joven, con 52 años. Creo que al final lo que tenía era un cáncer en el estómago o el esófago, por lo delgado y débil que se quedó en los últimos meses. Él pensaba que tenía cura; fuimos a muchos médicos, se puso varios tratamientos, pero al final yo creo que él se imaginaba que lo que tenía era malo. Antes de morir fue mayordomo de nuestra romería, con mucha fe y orgullo; lo tenía de promesa. Su muerte fue un duro golpe para todos pero sobre todo para mi madre, que se quedó sola muy joven y con muchas bocas que alimentar. Hemos trabajado en todo. Y, hace unos años, sufrimos otra pena muy grande, la muerte de uno de mis hermanos con sólo 47 años, enfermo del pulmón. Mi madre se moría de la pena. Y ahora yo... ella sabe que me voy a morir joven, $y$, aunque no me lo dice, lo veo en la tristeza de sus ojos cansados y en los suspiros que continuamente le salen... pobrecita. Está continuamente preguntándome cómo me encuentro, animándome a que coma más. ¡Es muy pesada! Pero muy buena...la mejor madre del mundo.

\section{HORAS DE CONSPIRACIÓN DE SILEN- CIO}

Supe que tenía cáncer porque me entró un dolor muy fuerte de ovarios que no era fácil de calmar y me vieron en ginecología. Vieron algo que no les gustó y me mandaron a otros especialistas y más pruebas. Me hicieron un TAC y un viernes me mandaron para casa para que volviera el lunes. A mí me resultaba un poco raro pero pensé que me tendrían que hacer más pruebas; en ningún momento quería pensar mal.'Me hicieron pruebas, eco, radiografías. Pero nadie habló conmigo, me fui a casa, era un fin de semana, me dijo que volviese el lunes, estábamos de reunión familiar, me acuerdo que había mucha comida, pero pasaba algo, la gente no estaba normal, mi marido estaba muy serio, mis cuñadas me mimaban mucho, yo ya me olía lo peor. Así que el lunes rompo tanto silencio, pregunto al oncólogo todo lo que estaba pasando, le dije que hablase claro, más pruebas, más pruebas y un largo peregrinaje de pruebas hasta que me dijeron lo que yo me temía, tengo cáncer y no tengo posibilidades de que me lo quiten".

\section{EL DIAGNÓSTICO, MI SENTENCIA DE MUERTE}

Cuando el oncólogo me dijo que tenía un cáncer en el estómago y que lo que tenía en los ovarios eran metástasis "Se me vino el mundo abajo, soy joven; primero pensé en el dolor de mi madre, viuda muy joven y con la pérdida de mi hermano... todavía no hace ni tres años". Pensé que mi madre no lo iba a soportar, eran demasiadas muertes para ella, con lo unidas que estamos las dos.

"Lo primero que hice fue pensar en mis hijos, luego en mi marido y luego en mis hermanosllora- esto no me puede pasar a mi"

"Me acuerdo de los potos que están en el pasillo del hospital, tengo esa imagen en mi cabeza, no podía creer lo que me estaba pasando, no parecía que fuera conmigo, y ahora qué?- le dije a Jose, mi marido". Ha sido uno de los días más dolorosos de mi vida, me hice todas las preguntas que no tienen respuestas: ¿Por qué a mí?, ¿No teníamos bastante con mi hermano y mi padre?, ¿ Acaso yo me lo merecía?, ¿ Cómo iban a tirar mi marido y mis hijos sin mí?... no era justo, la vida me pareció injusta, sin sentido. No paraba de fumar en aquel pasillo, llorando sola con Jose, pensando cómo iba a decírselo a mis hijos, a mi madre, a mis hermanos. Jose no sabía que decirme, solo me abrazaba. Se me vino todo el hospital encima, todo era feo, oscuro y muy frío.

\section{LA FE, MI GRAN ALIADA}

No pudieron operarme, me pusieron quimio y lo soporté. Estuve un tiempo muy repuesta. Yo era la que animaba a todo el mundo, he sido siempre el alma de las fiestas. Me hice Ermitaña de la Virgen 
de la Peña por promesa. Tengo mucha fe en la Virgen. Aquí se está divinamente, es lo más cerca que se puede estar de Ella y del cielo. Yo me encargo de cuidar la Ermita, de recibir a los fieles que vienen a visitarla, aquí puedes comprar recuerdos de Ella y tomarte un café en el bar; también tenemos comidas. También hay unas cuantas casas que se alquilan y nos llevamos un porcentaje del alquiler. Con lo que gano aquí ayudo en la economía de mi familia. Estoy orgullosa de mi hijo pueda afeitarse con maquinillas de las buenas.

"Tengo esperanzas de reponerme con la transfusión, para hacer mi romería, aunque estoy cansada, agotada, a veces me faltan fuerzas". Queda unos meses para la romería pero creo que voy a poder estar en ella y cumplir con mi papel. Soy muy fuerte, a pesar de que estoy viviendo más de lo que se esperaba de mi cáncer. No pienso en mi muerte, quiero pensar que me queda mucho por delante, para seguir viendo a mis hijos, a mi marido, a mi madre y a mis hermanos, y a mis amigas, y a todos los conocidos de mi pueblo. Soy muy sociable y me conoce toda la gente.

-Dominga quería llegar a la romería para poder acompañar a la virgen que pronto la tendrá cerca, era su máximo deseo, cuando llegó el momento ella estaba muy débil, pero la virgen no le falló, seguidamente os muestro un fragmento del periódico oficial de Huelva que describe lo que ocurrió el día de la romería de la Virgen de la Peña del 2008, el día de Dominga-

"La emoción contenida desde primeras horas de la mañana se demostró en las lágrimas de los romeros que acompañaban a la Virgen al llegar a uno de los enclaves más especiales del cerro. A pocos metros del Santuario vive la ermitaña, la encargada de cuidar a la Virgen y el entorno en el que vive. Pero este año, esta especial puebleña no ha podido salir a caminar ayer al lado de su Patrona por encontrares enferma. Por ello, este año, la Virgen quiso ser Ella la que se acercara a la ermitaña. El paso dio media vuelta, se acercó a la ventana de la casa de la ermitaña y, cuando los varales tocaron la pared, todos los romeros bajaron la cabeza con la intención de esconder las lágrimas que corrían por sus mejillas. Fue uno de los momentos más intensos de la procesión cuando los oles y los vivas sonaron con una intensidad especial. Las campanas de la ermita pronto se unieron a los cantos de los romeros y no cesaron hasta que la Virgen volvió a presidir el retablo dorado que se alza, grandioso, en el interior de su ermita"

Fuente: Huelva Información 23 abril 2008

\section{AFRONTAMIENTO DE LA FAMILIA. RES- PUESTAS HUMANAS}

A mi madre la veo siempre muy triste, sé que llora cuando está sola porque piensa en cómo dejaré todo cuando yo me vaya. Aunque intenta disimular se que vive ya la pena de que me voy a morir. Está muy nerviosa, con los suspiros, con los “Ay, dios mió! A cada rato. Me pregunta todo, y me anima a que me levante y coma mucho para estar fuerte. Me da mucha lástima verla tan triste.

A mi marido, a Jose, le veo preocupado aunque intenta que no se le note. Está siempre dispuesto a llevarme corriendo a cualquier médico o al hospital cada vez que me siento mal, pero le cuesta sentarse a hablar conmigo de mis cosas, de mi miedo, de mi pena. Eso le cuesta mucho a Jose, cómo explicarle que, a veces, le necesito más para que me escuche que para que me lleve al médico. Está siempre a mi lado, apenas se separa de mí porque yo quiero tenerle muy cerca, pero nos comunicamos poco en lo profundo, en lo que yo no puedo un hablar con mi madre, ni con mis amigas porque no llegamos nunca a profundizar, tal vez por miedo que tienen a no saber qué decirme, no?

Mi hijo mayor es el más cariñoso; está siempre abrazándome y achuchándome, preguntándome cómo estoy, animándome cuando me ve triste. Y también me cuenta cuando él está agobiado por mí. Me pregunta muchas veces cómo me siento y me cuenta siempre cómo se siente él.

Mi hija Carlota es la que más me preocupa, y Jose. Carlota está muy callada, cabreada la mayoría del tiempo, como enfadada con el mundo. Sé que está agobiada y tiene miedo de que yo me ponga más enferma todavía, a su edad no quieres que tu madre esté enferma, quieres una madre sana que esté contigo, verdad? Sé que lo pasará fatal, tiene una edad muy crítica para perder a su madre. Es fuerte y responsable; siempre ha sido una niña estupenda y sé que con los años lo superará pero lo va a pasar muy mal. Todas las mujeres sabemos lo importante que es nuestra madre para cada una. 
Mi pequeñín tiene 6 años y es el que menos entiende lo que pasará. Me da mucha pena no poder verle crecer, pero sé que con todo el cariño que los míos le darán, se repondrá pronto. Confía en que los médicos me pinchan para curarme.

Mis hermanos... también van a sentir mucho dolor, pobres. Menos mal que mi familia es una piña y sé que estarán todos juntos, ayudándose siempre.

Como ya he dicho antes "Necesito aprender a comunicarme con mi marido y mi hija, sé que lo están pasando mal, mi marido siempre ha sido muy bueno, pero no hablador, le da miedo preguntarme, y si me quejo lo único que quiere es llamar al médico para que sea éste el que resuelva el problema" espero conseguir despedirme bien de ellos.

\section{PROPIO AFRONTAMIENTO}

Cuando pienso en mi muerte, sólo sé que no quiero sufrir mucho ni que los míos sufran viéndome. No tengo ningún papel firmado con lo que quiero pero pienso que cuando no pueda aguantar más los médicos pueda dormirme para no sufrir mucho.

Sé que voy a morir pero tengo la esperanza de que mi muerte no esté cerca. Quiero vivir más tiempo, que pueda estar bien en la romería y después. Yo no pierdo las esperanzas, soy muy fuerte.

Sé que mi criatura (las metástasis), esa que se deja ver después de una paracentesis, va creciendo y me resta fuerzas y energía, pero cada día me levanto con ánimos para bajar al pueblo y llevar a mi hijo al colegio, para animar a mi madre, sonreír a mi marido, realizar las compras y saludar a mis paisanos.

Temo que mi enfermedad me haga sufrir molestias y mucho dolor.

Temo depender de otros para lavarme y vestirme, para moverme. No me gustaría que tuvieran que lavarme, siempre he sido muy independiente.

Llegado el momento deseo que me duerman para no sufrir.

Todo esto me hace disfrutar más intensamente de mis hijos, de mi marido, de toda mi familia, pero es duro tener que hacerse la fuerte para que ellos no se vengan abajo, es difícil subir cuando todo te tira hasta el fondo. Y el fondo es muy oscuro, a veces me da mucho miedo, pero no sé a quién contárselo, porque no quiero que sufran como yo.
Estoy agradecida porque todos se preocupan por mí, pero estoy sola, porque no puedo expresar abiertamente mi miedo a no controlar lo que se me viene encima.

Tengo miedo a que mi familia no siga económicamente adelante, sé que con el tiempo, mi cariño pueden dárselo otros, aprenderán a vivir sin mí, pero el dinero... nos ha costado siempre mucho, a mi madre y a mi familia salir a flote. Tenemos una casa terminada en el pueblo y eso me tranquiliza mucho, no están en la calle, es una buena vivienda, muy bonita y grande. Y tienen trabajo. Y mi hija va muy bien en sus estudios, en fin...

\section{IMAGEN CORPORAL}

No me preocupa mi aspecto físico, no me veo mal. Estoy muy delgada pero siempre he sido canija y muy alta. Estoy demacrada pero, como sigo maquillándome sigo siendo muy resultona...

Siempre he sido muy femenina, no salgo a la calle sin mi maquillaje, mis uñas impecables y mi perfume, por supuesto.

Me encuentro muy delgada pero ya he dicho que yo he sido canijilla. Me hace gracia, me divierte cuando la gente piensa que estoy embarazadaja,ja,ja- y después de la paracentesis parece que estoy recién parida.

Sé que sigo siendo atractiva porque la gente me lo dice continuamente, sé que mis ojos son muy expresivos, tan grandes y tan oscuros... y, como no paro de sonreír resulto más agraciada.

\section{LA ENFERMERÍA}

El personal sanitario que me he encontrado desde que me diagnosticaron el cáncer son todos estupendos. El oncólogo y las enfermeras de hospital de día muy amables todos, muy atentos. Pero... lo que yo me he encontrado en el Vázquez Díaz no me lo podía ni imaginar... "me dan carino, se acercan a mi, me acarician la mano, me hacen reír todas, hasta la limpiadora, tengo toda la flexibilidad en los ingresos, yo elijo cuando me voy de permiso al pueblo y cuando ingreso cuando me encuentro mal". No esperaba que hubiera personas tan cariñosas, me tratan como si me conocieran de toda la vida, no sé de donde les sale tanto cariño y tanta simpatía. Me sienta muy bien que entren en mi habitación por la mañana con una sonrisa, se sientan en mi cama, me cogen la mano 
y me preguntan cómo estoy, cómo me siento, qué me apetece desayunar y cómo lo voy a hacer para ducharme.... Los médicos me permiten irme de alta antes de la cuenta porque soy muy activa y lo que quiero es estar cuanto antes en mi peña, con mis niños y mi madre, en mi casa. Y cuando ya me siento que estoy demasiado llena y necesito vaciarme la barriga o ponerme sangre porque estoy muy débil, les llamo y de momento me dan cita. Son todos encantadores, les tengo un cariño especial.

Me ha gustado mucho hablar con vosotras equipo investigador- porque me habéis dado la oportunidad de descargarme de muchas cosas que no puedo compartir con apenas nadie. Con vosotras es fácil desahogarse y no sé si queréis que os cuente otras cosa o está bien con todo lo que me ha salido esta tarde, aquí solas las tres, en esta casa tan cerca de la Virgen y del cielo, en este lugar tan bonito de Huelva. A lo mejor otro día me sale hablaros de otras cosas, no sé, pero hoy me han salido, yo creo que bastantes. Me quedo como más relajada, muy a gusto de que me hayáis escuchado. Gracias.

Dominga estuvo presente en su romería, con muy pocas fuerzas físicas, pero todas en su corazón. Apenas podía mantenerse en pie y recibía a todos los que la visitaron sentada en el salón de su casa. No le negó a nadie su espléndida sonrisa.

Nos ingresó al día con un severo deterioro de su estado general, con caquexia extrema, úlcera por presión estadío I-II en glúteo por permanecer casi día y noche en el sofá para recibir a la gente. Sufría una obstrucción intestinal que le causaba náuseas y vómitos contínuos.

A pesar que durante la entrevista manifestó el deseo de ser sedada cuando llegara el momento, cuando llegó el momento cambió su discurso y en ningún momento quiso perder la conciencia, aún teniendo algunas molestias. Fue consumiéndose poco a poco, apagándose como una vela, encendida solo gracias a la esperanza de ver cada tarde a sus hijos, madre y hermanos que le daban fuerza cada tarde. Durante su aseo personal que realizábamos una enfermera y una auxiliar de enfermería, no nos faltaron nunca palabras de agradecimiento y su sonrisa.

Fue una mujer tremendamente generosa, siempre nos regaló su sonrisa.

Alguna de sus últimas frases:

"Gracias por vuestra paciencia y vuestra sonrisa" "Gracias por hacer de mi baño uno de los momentos del día donde más me río"

"Gracias por aplicarme el perfume en las zonas donde más me gustan"

"Gracias a mi marido por la paciencia que tiene conmigo"

"NO ME DURMÁIS TODAVÍA AUNQUE ESTÉ MOLESTA, NO TENGO FUERZAS, PERO... QUIERO DISFRUTAR UN POCO MÁS..."

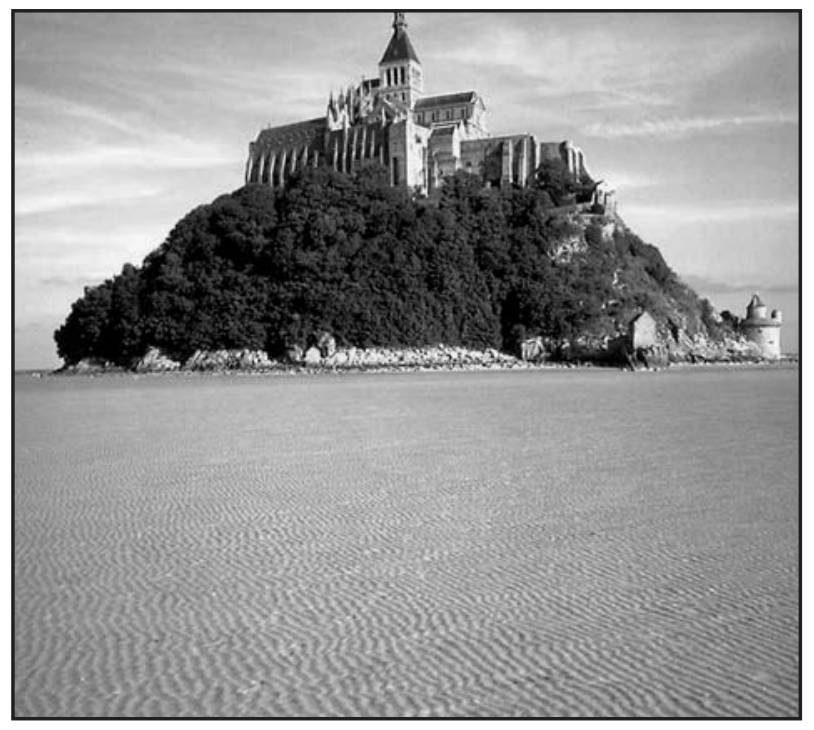

